\title{
Interstitial Irradiation of Skull Base Tumours
}

\author{
Mark Bernstein and Philip H. Gutin
}

\begin{abstract}
The rationale for interstitial irradiation of tumours in and around the skull base is reviewed, and the experience accumulated with pituitary adenomas, meningiomas, and chordomas is summarized. Intracystic irradiation for craniopharyngiomas is also reviewed.
\end{abstract}

RÉSUMÉ: Irradiation interstitielle des tumeurs de la base du crâne Nous passons en revue la raison d'être de l'irradiation interstitielle des tumeurs de la base du crâne ainsi que notre expérience avec les adénomes pituitaires, les méningiomes et les chordomes. Nous discutons aussi de l'emploi de l'irradiation intracyste dans le craniopharyngiome.

Can. J. Neurol. Sci. 1985; $12: 366-370$

The majority of meningiomas, acoustic schwannomas, and pituitary adenomas are extra-arachnoid, histologically low grade neoplasms which can be totally extirpated using microsurgical techniques. A certain number, however, because of size, location, and/or invasive biological behaviour are not amenable to gross total removal. The surgical curability of craniopharyngiomas remains controversial, ${ }^{1,2}$ and chordomas, although rare tumours, can seldom if ever be totally removed in spite of innovative and aggressive surgical procedures. ${ }^{3}$

Optimal surgical resection remains the initial treatment of choice for most tumours arising in and around the skull base. There is increasing evidence that adjuvant therapy with radiation can prevent or delay the recurrence of incompletely resected meningiomas, ${ }^{4-6}$ chordomas, ${ }^{7-9}$ and craniopharyngiomas. ${ }^{10,2,11}$ For pituitary adenomas, external beam irradiation has long been recognized to be an effective adjunct to subtotal resection. ${ }^{12}$ Excellent results have been obtained with irradiation in cases of endocrine-inactive pituitary adenomas ${ }^{13}$, prolactinomas, $^{14,15}$ Cushing's disease, ${ }^{16}$ and acromegaly. ${ }^{17}$ A number of different radiation techniques have been utilized in treating pituitary adenomas, including parallel opposed fields, three-field techniques, and arc rotational therapy.

The relative radioresistance of slow-growing, mitotically inactive neoplasms such as meningioma, chordoma, craniopharyngioma and schwannoma underscores the need for high tumour radiation doses in order to achieve maximum benefit. ${ }^{7}$ However, the brain's tolerance to radiation is finite, and the cure or sterilization of any tumour (malignant or low-grade) is beyond the capability of any radiation modality that affects not only the tumour but also adjacent brain and blood vessels. We must therefore attempt to improve upon conventional teletherapy, which cannot deliver the ionizing radiation in a sufficiently well focused volume to affect only the tumour and spare the brain.

There are a number of ways of improving the therapeutic ratio between tumour and surrounding brain: 1) focused gamma radiation from numerous narrow radiation beams that are stereotactically directed to a small target volume, ${ }^{18} 2$ ) accelerated charged particles which can be focused precisely using the Bragg peak technique, ${ }^{19}$ and 3) implantation of radiation sources within a tumour volume (i.e. interstitial brachytherapy). In this paper, we review the experience with interstitial radiation in the treatment of pituitary adenomas, meningiomas, and chordomas, and intracystic irradiation of craniopharyngiomas.

\section{Pituitary Adenoma}

A pituitary adenoma was the first intracranial neoplasm to be treated by brachytherapy; in 1911, after a trans-sphenoidal operation on a young woman with acromegaly, Hirsh inserted a radium-loaded probe through the nasal cavity into the sella turcica. ${ }^{20}$ Other early experiences included the free-hand placement of multiple $1 \mathrm{mCi}$ radon seeds into pituitary tumours, via frontal craniotomy; ${ }^{21}$ this author stated "the results obtained are not discouraging". Since that time, an extensive experience with interstitial irradiation of pituitary adenomas has accrued. ${ }^{22-25}$ A variety of radioisotopes have been used, but the most popular have been ${ }^{32} \mathrm{P},{ }^{90} \mathrm{Y},{ }^{198} \mathrm{Au}$, and ${ }^{192} \mathrm{Ir}$. Since the 1950's, the majority of cases have been done stereotactically.

Endocrinological results have been encouraging, particularly in acromegaly. Of 16 acromegalic patients treated with ${ }^{90} \mathrm{Y}$ implantation, half experienced improvement of the acrome-

From the Division of Neurosurgery, Toronto Western Hospital, University of Toronto (Dr. Bernstein) and The Brain Tumour Research Center of the Department of Neurological Surgery, University of California, San Francisco (Dr. Gutin)

Reprint requests to Dr. Mark Bernstein, 25 Leonard Ave., Ste. 211, Toronto, Ontario, Canada M5T 2R2 
galic features and headaches, while maintaining normal pituitary function. ${ }^{26}$ In a series of patients treated with ${ }^{198} \mathrm{Au}$ and ${ }^{90} \mathrm{Y}, 60 \%$ obtained improvement of the acromegalic features, although $40 \%$ ultimately required endocrine replacement therapy. ${ }^{27}$ In another series of 80 patients implanted between 1958 and $1967,53 \%$ showed clinical improvement; in $45 \%$ of patients glucose tolerance tests became normal. ${ }^{28}$ However, $59 \%$ of these patients continued to have growth hormone levels above $10 \mathrm{ng} / \mathrm{ml}$. In his large experience, Mundinger found clinical improvement in $96 \%$ of patients with endocrine-inactive adenomas, $92 \%$ of patients with Cushing's disease, and $76 \%$ of acromegalics. ${ }^{24}$

Visual impairment has also improved following brachytherapy of pituitary adenomas. In one large series, $87 \%$ of patients had stabilization or improvement of vision; patients treated for endocrine-inactive adenomas did slightly better than acromegalic patients. ${ }^{24,29}$

Among the complications of this technique are cranial nerve palsies, reported by Molinatti et al $(1962)^{26}$ in $13 \%$, and diabetes insipidus, seen in $38 \%$ of their cases. Other complications encountered include CSF rhinorrhea, pituitary abscess, and visual impairment. ${ }^{27}$

Stereotactic gamma radiosurgery has also been employed successfully in treating endocrine-inactive adenomas and prolactinomas $^{31}$ and Cushing's disease. ${ }^{32}$ Bragg peak proton radiation has similarly been utilized with excellent results in acromegaly, Cushing's disease, prolactinoma and endocrineinactive pituitary adenomas ${ }^{33}$ treatment with alpha particles (helium ions) has also been used since 1957 in a series of acromegalics. ${ }^{34}$

In summary, interstitial irradiation of pituitary adenomas has proved effective in controlling the endocrinopathy in over half of patients with acromegaly and Cushing's disease; experience with prolactinomas has been less extensive, due to the present high rate of surgical curability, and effective drug therapy with bromocriptine. Visual symptoms and signs can be corrected or stabilized in most patients. Interstitial brachytherapy of pituitary adenomas is at present more popular in Europe than it is in North America.

\section{Craniopharyngioma}

Interstitial irradiation has been used to control recurrent cyst formation in craniopharyngiomas by introducing radioisotopes into the cyst cavity. This technique was pioneered in the early 1950's and applied stereotactically by Leksell and Liden (1952). ${ }^{35}$ The initial agent used was phosphorus- $32^{36.37}$ but other isotopes have been introduced (Table 1). The ideal isotope for intracystic therapy would have a half-life of several days, beta energy low enough to ensure minimal tissue penetration, and no or minimal gamma emission. Yttrium- 90 is probably the most ideal isotope available at present, ${ }^{38.39,40.41}$ but recent work shows rhenium-186 to be promising. ${ }^{25,42,43}$ Advances in disimetry and methods of administration have also rekindled interest in gold-198 for intracystic irradiation. ${ }^{40.44}$

Intracystic isotope treatment is limited to those craniopharyngiomas with a medium to large thin-walled cystic component; intracystic therapy will have no beneficial effect on solid portions of tumour, or on thick or calcified cyst walls. The optimum dose to cause collapse of a cyst is yet to be determined; Bond et al concluded that the effective intracystic dose of ${ }^{198} \mathrm{Au}$ is $10-15 \mathrm{mCi}$ of colloidal gold. ${ }^{45}$ Another study with ${ }^{32} \mathrm{P}$ and ${ }^{90} \mathrm{Y}$ determined that the dose delivered to the cyst surface must exceed 100,000 rad to collapse the cyst. ${ }^{46}$ The method of calculation of the cyst wall dose depends on whether one assumes a uniform distribution of the colloidal isotope throughout the cyst volume, or uniform deposition of the isotope along the inner wall of the cyst, as demonstrated in Figure 1. ${ }^{36,40}$

Results of intracystic isotope therapy have been encouraging. Kobayashi et al injected ${ }^{198} \mathrm{Au}$ or ${ }^{32} \mathrm{P}$ via an Ommaya reservoir into the cyst in eight patients. The cyst volumes ranged from 5 to $120 \mathrm{~mL}$, and cyst wall thickness varied from 0.5 to $7.0 \mathrm{~mm}$. Isotope dosages were $10-20 \mathrm{mCi}$ of ${ }^{198} \mathrm{Au}$ and $2.3-5.0 \mathrm{mCi}$ of ${ }^{32} \mathrm{P}$; cyst wall doses were $6,000-100,000 \mathrm{rad}$. Results were considered excellent in six cases, and good in two, with a mean follow-up of 71 months. Only one complication was reported, an oculomotor nerve palsy in the patient with an accumulated cyst wall dose of $100,000 \mathrm{rad}$.

In summary, intracystic irradiation remains an effective and relatively safe means of controlling craniopharyngioma cysts; this technique might be particularly valuable in a patient who has received a course of conventional external beam radiation and develops a recurrent symptomatic cyst refractory to surgical management. Solid craniopharyngiomas have not been considered amenable to interstitial irradiation, although a limited experience using ${ }^{125} \mathrm{I}$ and ${ }^{192} \mathrm{Ir}$ implants has been reported. ${ }^{47}$ As
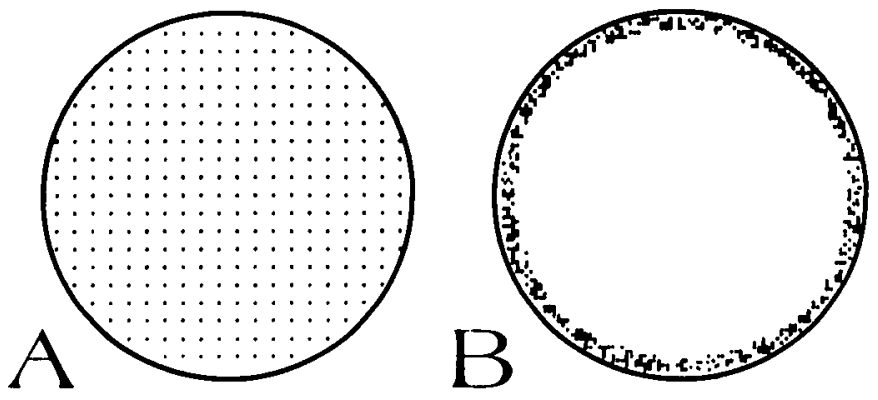

Figure 1-Models of distribution of colloidal radioisotope in a cystic tumor, for mathematical calculations of dose to cyst wall. A. uniform suspension, $B$. layering-out along cyst wall.

Table 1: Radioisotopes used for Intracystic Irradiation

\begin{tabular}{lccccc}
\hline \hline Isotope & $\begin{array}{c}\text { Half-life } \\
\text { (days) }\end{array}$ & $\begin{array}{c}\text { Maximum beta } \\
\text { energy (MeV) }\end{array}$ & $\begin{array}{c}\text { Mean beta } \\
\text { energy (MeV) }\end{array}$ & $\begin{array}{c}\text { Beta half-value } \\
\text { in tissue (mm) }\end{array}$ & $\begin{array}{c}\text { Gamma energy } \\
(\mathrm{MeV})\end{array}$ \\
\hline Gold-198 $\left({ }^{198} \mathrm{Au}\right)$ & 2.7 & 1.37 & 0.32 & 0.4 & 0.41 \\
Phosphorus-32 $\left({ }^{32} \mathrm{P}\right)$ & 14.3 & 1.71 & 0.69 & 0.8 & 0.4 \\
Rhenium-186 $\left({ }^{186} \mathrm{Re}\right)$ & 3.7 & 1.07 & 0.36 & 0.14 \\
Yttrium-90 $\left({ }^{90} \mathrm{Y}\right)$ & 2.7 & 2.27 & 0.93 & -1.1 & - \\
\hline
\end{tabular}


well, stereotactic gamma radiosurgery has been tried in a series of nine patients, eight of whom had predominantly solid tumours. ${ }^{30}$

\section{Meningioma}

Experience with interstitial irradiation of meningiomas has been very limited. The first radioactive implantation of a meningioma was performed around 1918 by Frazier who reported that his results with "endotheliomata" were more encouraging than with gliomas; ${ }^{48}$ the largest experience has been reported by Mundinger. ${ }^{49.47}$ Most of the cases were implanted either because of unfavourable pathology (angioblastic or malignant features) or because of incomplete surgical resection, and the isotope used was either ${ }^{192} \mathrm{Ir}$ or ${ }^{125} \mathrm{I}$, implanted intraoperatively. It was Mundinger's impression that brachytherapy caused the tumours to shrink and become better demarcated (as documented at repeat craniotomy).

Currently, one of the authors (PHG), is conducting a clinical trial of reirradiation of recurrent tumours of the skull base with interstitially implanted ${ }^{125}$ I sources. Since March 1981, seven patients with recurrent, life-threatening, inoperable, basal meningeal tumours have been treated (two meningiomas, three malignant meningiomas, two meningeal sarcomas). All patients had previously received maximal surgical resection and external radiation $(5,000-6,000 \mathrm{rad})$. Five patients were treated with multiple ( 9 to 36 ) permanent, low-activity seeds implanted at open craniotomy; total doses delivered to the periphery of the lesions were 8,000 to $15,000 \mathrm{rad}$. Two patients with recurrent malignant meningiomas of the fal $x$ were stereotactically implanted with removable high-activity ${ }^{125}$ I sources to produce peripheral tumour doses of 5,000 and $11,000 \mathrm{rad}$. Of the seven patients, two developed regrowth of the tumour outside the treated volume, and one other deteriorated from radiation necrosis one year following implant. The other four, and the patient operated on for focal radiation necrosis have remained stable during a mean follow-up of 24 months after brachytherapy. As part of the same trial, two recurrent meningeal neoplasms have been treated with charged particles (helium and neon); one patient developed radiation necrosis at 16 months and the other had tumour recurrence at 19 months.

\section{Chordoma}

Experience with interstitial irradiation of chordomas is even less extensive than with meningiomas. The first reported chordoma treated by this method was in Montreal in $1938 .{ }^{50} \mathrm{~A}$ chordoma extending into the nasopharynx was implanted with six $1 \mathrm{mCi}$ radon seeds combined with 4,000 rad external radiation. A few months later, four more $1 \mathrm{mCi}$ radon seeds were implanted, ultimately resulting in the shrinkage of the nasopharyngeal portion of the tumour to one fifth its original size. The first stereotactic implantation of an intracranial chordoma was performed following stereotactic biopsy of a clivus lesion in a young man with headaches and cranial nerve palsies. ${ }^{51}$ Five ${ }^{90} \mathrm{Y}$ seeds (each $5-6 \mathrm{mCi}$ ) were deposited in the tumour and at follow-up nine months later, the patient was symptom free. Intraoperative implantation of permanent radioisotope sources has also been employed as adjuvant therapy in a few cases of spinal chordoma. ${ }^{52}$

In the current trial cited above, one of the authors (PHG) has implanted five recurrent clivus chordomas with multiple permanent, low-activity $(0.5 \mathrm{mCi})$ iodine- 125 sources to deliver estimated peripheral tumour doses of 5,000-15,000 rad. Two patients developed tumour recurrence 19 and 28 months after treatment; two others died of other causes but their tumours were not progressing, and one patient died early of progressive tumour growth outside the irradiated volume. Recurrent clivus chordomas have also been treated with helium ion irradiation ${ }^{53}$ and protons. ${ }^{8}$

\section{Acoustic Schwannoma and other tumours}

In 1914, Frazier implanted 85 mg of radium into an "inoperable tumour of the pontile angle", and then removed the radium 15 hours later; this may represent the first implantation of an acoustic schwannoma. ${ }^{48}$ Since then, there has been little interest in interstitial irradiation of these tumours, but stereotactic radiosurgery of these lesions with focused gamma beams ${ }^{54,55}$ has recently been reported; particle beam therapy has also been tried. ${ }^{56}$ In the series reported by Noren et al, 14 acoustic schwannomas were given doses up to $125,000 \mathrm{rad}$. The results were encouraging in that eight (57\%) had radiologically documented decrease in tumour size; one patient experienced improvement in auditory acuity. Cranial nerve complications were significant: two patients had trigeminal nerve, and five had facial nerve dysfunction. Barcia-Salorio et al reported 16 patients who received tumour doses of $72,000-90,000 \mathrm{rad}$. Reduction in tumour size was documented radiologically in six $(38 \%)$, the response being better in patients with tumours smaller than 3 $\mathrm{cm}$ diameter. Only one side effect occurred - a case of trigeminal neuralgia which responded to medication.

Other low-grade or histologically benign tumours have occasionally been implanted with radioisotopes. These include hemangioblastoma,${ }^{57}$ choroid plexus papilloma of the fourth ventricle, ${ }^{58}$ epidermoid, ${ }^{59}$ germinomas, ${ }^{60}$ and teratoma. ${ }^{25}$ As well, intra operative ${ }^{125}$ I implants of the skull base have been employed to control invasive or recurrent oropharyngeal and parotid malignancies. ${ }^{61}$

\section{Discussion}

A dose-response relationship has been demonstrated in conventional teletherapy of malignant gliomas; ${ }^{62}$ cohorts of patients who received higher doses of radiation had longer median survivals than cohorts of patients who received smaller doses. There may also be a dose-effect response in radiotherapy of certain low-grade skull base tumours. ${ }^{7.63}$ It seems desirable to deliver as large a dose as is deemed safe to the tumour volume in order to prevent or delay recurrence, and this goal may be achievable using interstitial radioisotope implants. Considerable experience has now accrued with interstitial brachytherapy of gliomas. ${ }^{49,64,25,47,65,66}$

Interstitial brachytherapy provides an enhanced therapeutic ratio between tumour and normal tissue, because of the favourable radiobiology of low dose-rate radiation, and the radiophysics of intratumoral location of the radioactive source. ${ }^{64,65}$ Low dose-rate radiation from interstitial implants $(<10 \mathrm{rad} / \mathrm{minute}$ as compared to $200 \mathrm{rad} /$ minute in conventional cobalt teletherapy) is better tolerated by normal than neoplastic tissue because the ongoing repair of sublethal radiation damage is performed more effectively by normal than neoplastic cells. ${ }^{67}$ Furthermore, the inverse-square law which applies to any point source of radiant energy, and tissue attenuation of radiation, both cause a rapid fall-off of radiation dose outside the target volume; therefore, a radioactive source placed directly into a tumour can deliver a 
maximum therapeutic dose to the tumour, with relative sparing of the surrounding normal tissues. This normal tissue sparing is of great importance, since the major normal-tissue complications of therapeutic irradiation appear to be dose-related ${ }^{68,69}$

What conclusions can be drawn from the experience accumulated with interstitial irradiation of low grade neoplasms, in and around the skull base? For pituitary adenomas, both endocrineactive and -inactive, this modality is effective and has an acceptable complication rate in most series. However, due to advances in microneurosurgical techniques, improved drug therapies, and the excellent results with conventional external beam radiation, the role of interstitial irradiation in the treatment of pituitary adenomas is uncertain. Perhaps it is most appropriate in invasive, aggressive adenomas which recur after surgery and external beam teletherapy.

For craniopharyngiomas, there is a definite role for the administration of intracystic radioisotopes for control of recurrent cysts which are compressing neural structures, and are refractory to surgery and external irradiation.

Evaluation of interstitial irradiation in the treatment of basal meningiomas and chordomas is difficult because of the somewhat variable and unpredictable biological behaviour of these lesions. When a meningioma or chordoma recurs after maximal surgical removal and external irradiation, the options for treatment are limited. Repeated surgical decompression becomes difficult and dangerous with progressive distortion of surgical anatomy, and further external beam teletherapy carries a high risk of damage to normal tissue. Interstitial radiation provides an alternative treatment. However, during surgical exposure of these difficult tumours, the surgeon cannot predict the exact tumour volume and therefore correctly place the radioactive sources. Dosimetry planning can be greatly improved by stereotactically placing high-activity removable implants into a CT-defined target volume, but the skull base area is relatively inaccessible to the stereotactic surgeon. If inadequate doses are delivered to the entire tumour volume, tumour recurrence will likely occur; on the other hand, if normal tissue is included in the target volume, serious radiation necrosis may ensue..$^{68,66}$ The consequences of damage to normal tissue in the skull base region are greater than in the supratentorial compartment because of the presence of many large arteries and cranial nerves. The indications and methods of interstitial irradiation for recurrent basal tumours therefore remain unresolved, but the theoretical and practical advantages of this technique will hopefully result in more extensive clinical trials which should help to define them more precisely.

\section{REFERENCES}

1. Hoffman HJ, Hendrick EB, Humphreys RP et al. Management of craniopharyngioma in children. J Neurosurg 1977; 47:218-277.

2. Fishcher EG, Welch $\mathrm{K}$, Belli JA et al. Treatment of craniopharyngiomas in children: 1972-1981. J Neurosurg 1985; 62:496-501.

3. Derome PJ. The transbasal approach to tumors invading the base of the skull. In: Schmidek HH, Sweet WH, eds. Operative Neurosurgical Techniques. Indications, Methods and Results. New York: Grune and Stratton, 1982: 357-379.

4. Wara WM, Sheline GE, Newman $\mathrm{H}$ et al. Radiation therapy of meningiomas. Am J Radiol 1972; 123:453-458.

5. Carella RJ, Ransohoff J, Newall J. Role of radiation therapy in the management of meningioma. Neurosurgery 1982; 10:332-339.

6. Petty AM, Kun LE, Meyer GA. Radiation therapy for incompletely resected meningiomas. J Neurosurg 1985; 62:502-507.
7. Pearlman AW, Friedman M. Radical radiation therapy of chordoma. Am J Radiol 1970; 108:333-341.

8. Suit HD, Goitein M, Munzenrider J et al. Definitive radiation therapy for chordoma and chondrosarcoma of base of skull and cervical spine. J Neurosurg 1982; 56:377-385.

9. Cummings BJ, Hodson I, Bush RS. Chordoma: The results of megavoltage radiation therapy. Int J Rad Onc Biol Phys 1983; 9:633-642.

10. Richmond IL, Wara WM, Wilson CB. Role of radiation therapy in the management of craniopharyngiomas in children. Neurosurgery $1980 ; 6: 513-517$.

11. Manaka S, Teramoto A, Takakura $K$. The efficacy of radiotherapy for craniopharyngioma. J Neurosurg 1985; 62:648-656.

12. Sheline GE, Tyrell B. Pituitary adenomas. In: Phillips TL, Pistenma DA, eds. Radiation Oncology Annual. New York: Raven Press, 1983: 1-35.

13. Sheline GE. Treatment of nonfunctioning chromophobe adenomas of the pituitary. Am J Radiol 1974; 120:553-661.

14. Kleinberg DL, Noel GL, Frantz AG. Galactorrhea: A study of 235 cases including 48 with pituitary tumors. New Eng J Med 1977; 296:589-600.

15. Lundberg PO, Drettner B, Hemmingsson A et al. The invasive pituitary adenoma. A prolactin-producing tumor. Arch Neurol $1977 ; 34: 742-749$.

16. Jennings AS, Liddle GW, Orth DN. Results of treating childhood Cushing's disease with pituitary irradiation. New Eng J Med 1977; 297:957-962.

17. Eastman RC, Gorden P, Roth J. Conventional supervoltage irradiation is an effective treatment for acromegaly. J Clin Endocrin Metab 1979; 48:931-940.

18. Leksell L. Stereotaxis and Radiosurgery. An Operative System. Springfield, Ohio: Charles C. Thomas, 1971.

19. Tobias CA. Heavy particle irradiation of intracranial lesions. Radiosurgery with charged particles: Physical principles and techniques. In: Wilkins RH, Rengachary SS, eds. Neurosurgery. New York: McGraw-Hill Book Co., 1985: 1113-1119.

20. Hirsch O. Die operative Behandlung von Hypophysistumoren: Nach endonasalen Methoden. Arch Laryngol Rhinol 1912; 26:529-686.

21. Rawling LB. A contribution to the surgery of the pituitary region. An account of four cases of pituitary tumor treated by radon seeds. Br J Surg 1932; 19:68-77.

22. Tournoux $P$. L'implantation stereotaxique d'isotopes radioactifs. In: Guiot G, ed. Adenomes Hypophysaires. Paris: Masson et Cie, 1958: 247-262.

23. Joplin GF, Fraser R, Steiner R et al. Partial pituitary ablation. By needle implantation of gold-198 seeds for acromegaly and Cushing's disease. Lancet 1961; 2:1277-1280.

24. Mundinger F. Interstitial curie-therapy in the treatment of pituitary adenomas and for hypophysectomy. Prog Neurol Surg 1975; 6:326-379.

25. Mundinger F. Implantation of radioisotopes (curie-therapy). In: Schaltenbrand G, Walker AE, eds. Stereotaxy of the Human Brain. Anatomic, Physical and Clinical Applications. Stuttgart: George Thieme Verlag, 1982: 410-435.

26. Molinatti GM, Camanni F, Massara F et al. Implantation of yttrium-90 in the sella turcica in sixteen cases of acromegaly. J Clin Endocrin Metab 1962; 22:599-611.

27. Hartog M, Doyle F, Fraser R et al. Partial pituitary ablation with implants of gold-198 and yttrium-90 for acromegaly. Br Med J $1965 ; 2: 396-398$.

28. Wright $A D$, Hartog $M$, Palter $H$ et al. The use of yttrium-90 implantation in the treatment of acromegaly. Proc R Soc Med 1970; 63:221-223.

29. Mundinger $F$, Busam $B$. Stereotactic interstitial iridium-192 permanent implantation of pituitary adenomas. In: Szikla G, ed. Stereotactic Cerebral Irradition. Amsterdam: Elsevier/NorthHolland Biomedical Press, 1979: 187-197.

30. Backlund E-O. Solid craniopharyngiomas treated by stereotactic radiosurgery. In: Szikla G, ed. Stereotactic Cerebral Irradiation Amsterdam: Elsevier/North-Holland Biomedical Press, 1979 271-281.

31. Backlund E-O, Bergstrand $G$, Hierton-Laurell $U$ et al. Tumor changes after single dose irradiation by stereotactic radiosurgery in "non-active" pituitary adenomas and prolactinomas. In: 
Szikla G, ed. Stereotactic Cerebral Irradiation. Amsterdam: Elsevier/North-Holland Biomedical Press, 1979: 199-212.

32. Rahn T, Thoren $\mathbf{M}$, Hall $\mathrm{K}$ et al. Stereotactic radiosurgery in the treatment of MB Cushing. In: Szikla G, ed. Stereotactic Cerebral Irradiation. Amsterdam: Elsevier/North-Holland Biomedical Press, 1979: 207-212.

33. Kjellberg RN. Stereotactic Bragg peak proton radiosurgery results. In: Szikla G, ed. Stereotactic Cerebral Irradiation. Amsterdam: Elsevier/North-Holland Biomedical Press, 1979: 233-240.

34. Linfoot JA, Lawrence JH. Heavy particle irradiation of intracranial lesions. Treatment of functioning pituitary tumors. In: Wilkins RH, Rengachary SS, eds. Neurosurgery. New York: McGrawHill Book Co., 1985: 1119-1126.

35. Leksell $\mathbf{L}$, Liden $\mathrm{K}$. Therapeutic trial with radioactive isotopes in cystic brain tumor. In: Radioisotope Techniques, Vol. 1. Medical and Physiological Applications. London: Her Majesty's Stationary Office, 1953: 76.

36. Wycis HT, Robbins R, Spiegel-Adolf $M$ et al. Studies in stereoencephalotomy III. Treatment of a cystic craniopharyngioma by injections of radioactive $\mathrm{P}^{32}$. Confina Neurologica 1954; 14:193-202.

37. Overton MC, Sheffel DD. Recurrent cystic formation in craniopharyngioma treated with radioactive chomic phosphate. Case report. J Neurosurg. 1963; 20:707-710.

38. Backlund E-O. Studies on craniopharyngiomas: III. Stereotaxic treatment with intracystic yttrium-90. Acta Chir Scand 1973; 139:237-247.

39. Backlund E-O. Stereotaxic treatment of craniopharyngiomas. Acta Neurochir 1974; suppl. 21:177-183.

40. Kobayashi T, Kageyama N, Ohara K. Internal irradiation for cystic craniopharyngioma. J Neurosurg 1981: 55:896-903.

41. Huk WJ, Mahlstedt J. Intracystic radiotherapy $\left({ }^{90} \mathrm{Y}\right)$ of craniopharyngiomas: CT-guided stereotactic implantation of indwelling drainage system. Am J Neuroradiol 1983; 4:803-806.

42. Netzeband G, Sturm V, Georgi P et al. Results of stereotactic intracavitary irradiation of cystic craniopharyngiomas. Comparison of the effects of yttrium-90 and rhenium-186. Acta Neurochir 1984; suppl. 33:341-344.

43. Szikla G, Musolino A, Mujahara $S$ et al. Colloidal rhenium-186 in endocavitary beta irradiation of cystic craniopharyngiomas and active glioma cysts. Long term results, side effects, and clinical dosimetry. Acta Neurochir 1984; suppl. 33:331-339.

44. Kodama T, Matsukado Y, Uemura S. Intracapsular irradiation therapy of craniopharyngiomas with radioactive gold: Indication and follow-up results. Neuro Med Chir(Tokyo) 1981;21:49-58.

45. Bond WH, Richards $D$, Turner $E$. Experiences with radioactive gold in the treatment of craniopharyngioma. J Neurol Neurosurg \& Psych 1965; 28:30-38.

46. Leksell L, Backlund E-O, Johansson L. Treatment of craniopharyngiomas. Acta Chir Scand 1967; 133:345-350.

47. Mundinger $F$, Weigel $K$. Long term results of stereotactic interstitial curietherapy. Acta Neurochir 1984; suppl. 33:367-371.

48. Frazier $\mathrm{CH}$. The effects of radium emanations upon brain tumors. Surg Gyn Obs 1920; 31:236-239.

49. Mundinger $F$. The treatment of brain tumors with radioisotopes. Prog Neurol Surg 1966; 1:202-257.

50. Boldrey E, McNally WJ. Chordoma of the basiocciput and basisphenoid. Report of four cases. Arch Otolaryng 1941; 33:391-340.
51. Zoltan L, Fenyes I. Stereotactic diagnosis and radioactive treatment in a case of spheno-occipital chordoma. J Neurosurg 1960 17:888-900.

52. Sundaresan N, Galicich JH, Chu FCH et al. Spinal chordomas. J Neurosurg 1979; 50:312-319.

53. Castro JR, Saunders WM, Chen GT et al. Heavy particle irradiation of intracranial lesions. Malignant gliomas and other tumors. In: Wilkins RH, Rengachary SS, eds. Neurosurgery. New York: McGraw-Hill Book Co., 1985: 1126-1128.

54. Noren G, Arndt J, Hindmarsh T. Stereotactic radiosurgery in cases of acoustic neurinoma: Further experiences. Neurosurgery $1983 ; 13: 12-22$

55. Barcia-Salorio JL, Hernandez G. Ciudad J et al. Stereotactic radiosurgery in acoustic neurinoma. Acta Neurochir 1984; suppl. 33:373-376.

56. Castro JR, Quivey JM, Lyman JT et al. Current status of clinical particle radiotherapy at Lawrence Berkeley Laboratory. Cancer $1980 ; 46: 633-641$

57. Correll JW, Chase NE, Atkins HL. New technique for interstitial irradiation of brain tumors. J Neurosurg 1961; 18:800-803.

58. Ross JP. The treatment of cerebral tumors with radium. Br J Surg $1931 ; 18: 618-635$.

59. Talairach J, Ruggiero G, Aboulker $J$ et al. A new method of treatment of inoperable brain tumors by stereotaxic implantation of radioactive gold - a preliminary report. Br J Radiol 1955; 28:62-74.

60. Frank F, Gaist G, Piazza G et al. Stereotaxic biopsy and radioactive implantation for interstitial therapy of tumors of the pineal region. Surg Neurol 1985; 23:275-280.

61. Goffinet DR, Martinez A, Pooler D et al. Intraoperative pterygopalatine interstitial ${ }^{125}$ I seed implants. Int J Rad Onc Biol Phys 1983; 9:103-106.

62. Walker MD, Strike TA, Sheline GE. An analysis of dose - effect relationship in the radiotherapy of malignant gliomas. Int J Rad Onc Biol Phys 1979; 5:1725-1731.

63. Onoyama Y, Ono K, Yabumoto $E$ et al. Radiation therapy of craniopharyngioma. Radiology 1977; 125:799-803.

64. Bernstein M, Gutin PH. Interstitial irradiation of brain tumors: A review. Neurosurgery 1981; 9:741-750.

65. Gutin PH, Bernstein M. Stereotactic interstitial brachytherapy for malignant brain tumors. In: Rosenblum ML, Wilson CB, eds. Progress in Experimental Tumor Research. Brain Tumor Therapy. Basel, Switzerland: S. Karger, 1984: 166-182.

66. Gutin PH. Phillips TL, Wara WM et al. Brachytherapy of recurrent malignant brain tumors with removable high activity iodine-125 sources. J Neurosurg 1984; 60:61-68.

67. Fu KK, Phillips TL, Kane $\mathrm{LJ}$ et al. Tumor and normal tissue response to irradiation in vivo: Variation with decreasing dose rates. Radiology 1972; 114:709-716.

68. Marks JE, Baglan RJ, Prassad SC et al. Cerebral radionecrosis: Incidence and risk in relation to dose, time fractionation and volume. Int J Rad Onc Biol Phys 1981; 7:243-252.

69. Bernstein M, Perrin RG, Platts ME et al. Radiation-induced cerebellar chondrosarcoma. Case report. J Neurosurg 1984;61:174-177. 